Respiration 2011;81:262

DOI: $10.1159 / 000321227$

\section{Weight Is a Questionable Predictor of Alveolar Membrane Diffusing Capacity and Pulmonary Capillary Blood Volume Even in Moderately Obese Subjects}

\section{Gerald S. Zavorsky}

Human Physiology Laboratory, Marywood University, and The Commonwealth Medical College, Scranton, Pa., USA

I read with great interest the article by Rouatbi et al. [1] on the development of reference equations for alveolar membrane diffusion capacity and pulmonary capillary blood volume in a NorthAfrican population. I think it was a necessary study to perform. However, I would like to comment on some aspects of their study. First, they have examined their data and compared their results to previously published reference equations from the Netherlands [2] and France [3]. This is appropriate, but they did not compare their reference equations to those published by our group in North America [4]. It would have been more comprehensive to include our data from Canada [4] in their discussion.

My second comment pertains to their predictors for the reference equations. When examining their data in table 2, weight had no influence on determining pulmonary capillary blood volume or alveolar membrane diffusing capacity in females. These results are consistent with our work and the work from the Netherlands [2] and France [3]. However, the data of Rouatbi et al. [1] do show a weight influence on alveolar membrane diffusing capacity and pulmonary capillary blood volume in males which contradict the data of our [4] and two other studies [2,3]. What is their explanation for this contradiction between the existing literature and their data, especially when the standard deviation in weight for their sample is similar to other data sets of reference equations in which weight is not a factor $[2,4]$ ? Even the European reference equations used obese category II (body mass index $=30.0-34.9$ ) subjects in their data set, and weight is not a significant predictor of alveolar membrane diffusing capacity and pulmonary capillary blood volume [3]. Furthermore, why did Rouatbi et al. [1] find that weight is a prognosticator in men but not women? When examining their data, weight is the weakest (yet statistically significant) independent influence in their male reference equations. However, removing weight from their reference equations changes the predicted value by a large amount. How is this possible?

My third comment has to do with the method section of their paper. They reported that their data are based on American Thoracic and European Respiratory Society guidelines in which the average value of two trials whose difference in diffusing capacity is within $10 \%$ of each other is considered acceptable [5]. However, since the variability in the parameters pulmonary diffusing capacity for nitric oxide (which is an index for alveolar membrane diffusing capacity) and pulmonary diffusing capacity for carbon monoxide are independent of the magnitude of the measurement [6], the results invalidate the use of the percentage value to describe the repeatability. Using a percentage will lead to underestimation of variability in low values and overestimation in high values. Others have also suggested using an absolute value rather than a percentage since the diffusing capacity is independent of the magnitude of the measurement $[7,8]$. We therefore recommend using an absolute difference rather than a percentage as alternative criteria for repeatability [6]. We also recommend reporting the average of two trials when the absolute difference between the two measurements is within $17 \mathrm{ml} / \mathrm{min} / \mathrm{mm} \mathrm{Hg}$ for pulmonary diffusing capacity for nitric oxide; $3 \mathrm{ml} / \mathrm{min} / \mathrm{mm} \mathrm{Hg}$ for pulmonary diffusing capacity for carbon monoxide; $7 \mathrm{ml} /$ $\mathrm{min} / \mathrm{mm} \mathrm{Hg}$ for alveolar membrane diffusing capacity for carbon monoxide, and $13 \mathrm{ml}$ for pulmonary capillary blood volume [6].

My final comment pertains to the number of pulmonary diffusion tests performed in a single session. Why did Rouatbi et al. [1] have each subject perform five sequential diffusion tests? Pulmonary capillary blood volume and pulmonary diffusing capacity for carbon monoxide are significantly reduced by 7 and $1.2 \mathrm{ml} /$ $\mathrm{min} / \mathrm{mm} \mathrm{Hg} \mathrm{(5 \% ),} \mathrm{respectively,} \mathrm{after} \mathrm{only} \mathrm{four} \mathrm{trials} \mathrm{[6].} \mathrm{Therefore,}$ it would seem a fewer number of trials performed in a given session would be a better strategy to avoid reductions in these parameters.

\section{References}

1 Rouatbi S, Ben Saad H, Latiri I, Tabka Z, Guenard H: North-African reference values of alveolar membrane diffusion capacity and pulmonary capillary blood volume. Respiration 2010;80:301-312.

2 Zanen P, van der Lee L, van der Mark T, van den Bosch JM: Reference values for alveolar membrane diffusion capacity and pulmonary capillary blood volume. Eur Respir J 2001;18:764-769.

- 3 Aguilaniu B, Maitre J, Glenet S, Gegout-Petit A, Guenard H: European reference equations for CO and no lung transfer. Eur Respir J 2008;31: 1091-1097.

4 Zavorsky GS, Cao J, Murias JM: Reference values of pulmonary diffusing capacity for nitric oxide in an adult population. Nitric Oxide 2008; 18:70-79.

5 Macintyre N, Crapo RO, Viegi G, Johnson DC, van der Grinten CP, Brusasco V, Burgos F, Casaburi R, Coates A, Enright P, Gustafsson P, Hankinson J, Jensen R, McKay R, Miller MR, Navajas D, Pedersen OF, Pellegrino R, Wanger J: Standardisation of the single-breath determination of carbon monoxide uptake in the lung. Eur Respir J 2005;26: $720-735$.

-6 Zavorsky GS, Murias JM: A small amount of inhaled nitric oxide does not increase lung diffusing capacity. Eur Respir J 2006;27:1251-1257.

7 Robson AG, Innes JA: Short term variability of single breath carbon monoxide transfer factor. Thorax 2001;56:358-361.

8 Punjabi NM, Shade D, Patel AM, Wise RA: Measurement variability in single-breath diffusing capacity of the lung. Chest 2003;123:1082-1089.

Gerald S. Zavorsky, PhD

Marywood University

2300 Adams Avenue

Scranton, PA 18509 (USA)

Tel. +1 570961 4592, Fax +1 5703406067

E-Mail zavorsky@marywood.edu

\section{KARGER}

Fax +4161306 1234

E-Mail karger@karger.ch

www.karger.com
(C) 2010 S. Karger AG, Basel

$0025-7931 / 11 / 0813-0262 \$ 38.00 / 0$

Accessible online at:

www.karger.com/res 